\title{
Beneficiamento de uma argila tipo paligorskita da bacia de S. Luis-Grajaú, região de Alcântara, MA, e sua utilização como adsorvente de fósforo
}

\section{(Processing methods of a palygorskite clay from S. Luis-Grajaú basin, Alcantara, MA, Brazil, and its use as a phosphorus adsorbent)}

\author{
G. M. A. Rodrigues, R. F. Neves, R. S. Angélica \\ Instituto de Geociências, Laboratório de Caracterização Mineral, Universidade Federal do Pará, Rua Augusto \\ Corrêa, s/n, 66075-110, Belém, PA, Brasil \\ gabrielamonice@yahoo.com.br,rfn@ufpa.br,angelica@ufpa.br
}

\begin{abstract}
Resumo
Este trabalho utilizou uma amostra proveniente da bacia de S. Luis-Grajaú, MA, que consiste numa mistura na qual há predominantemente palygorskita e dolomita, abordando a existência desta nova ocorrência, sugerindo um método de beneficiamento e sua aplicação como adsorvente de fósforo para utilização na agricultura, já que a dolomita funciona como corretor de solos, enquanto a palygorskita tem a função de carreador de nutrientes. Primeiramente foi feita a caracterização química e mineralógica por meio de análise de difração de raios X, fluorescência de raios X, microscopia eletrônica de varredura, e separação das frações de areia, silte e argila. Foram ainda realizados ensaios de decantação e de adsorção de fósforo, com determinação da curva cinética. Após a análise de difração de raios X pode-se afirmar que a amostra é constituída principalmente de palygorskita e dolomita, apresentando também ilita, clorita e quartzo. Também foi possível verificar que os diferentes tipos de desagregação utilizados não apresentaram diferenças significativas nos difratogramas de raios X das amostras. Quanto à separação areia-silte-argila, apesar de se basear somente na granulometria, apresentou uma eficiência razoável na separação mineralógica, assim como os ensaios de decantação, onde se verificou que após 24 h a dolomita praticamente desaparece do sobrenadante. A determinação da curva cinética de adsorção mostrou que 2 h não é suficiente para que haja a adsorção do fósforo, sendo necessárias 24 h para atingir o equilíbrio da reação. Os ensaios de adsorção de fósforo mostraram eficiência acima de $91 \%$ do fósforo inicialmente presente na solução e o valor máximo adsorvido por grama da amostra foi de $0,607 \mathrm{mg}$. A correlação com os modelos de isotermas de adsorção estudados mostrou melhor resultado para a isoterma de Langmuir-Freundlich, com coeficiente de correlação 0,9993, o que pode ser atribuído ao fato da adsorção ocorrer em mais de uma camada.
\end{abstract}

Palavras-chave: palygorskita, dolomita, adsorção, fósforo, agricultura.

\section{Abstract}

This study used a sample from the basin of S. Luis-Grajaú, Maranhão state, Brazil,consisting of a mixture of predominantly palygorskite and dolomite, approaching the existence of this new occurrence, suggesting a processing method and its application as phosphorus adsorbent, once dolomite is a pH soil corrector while palygorskite has the function of nutrients carrier. First, chemical and mineralogical characterizations were performed by X-ray diffraction, X-ray fluorescence, scanning electron microscopy and separation of sand, silt and clay fractions. Sedimentation and phosphorus adsorption experiments were also performed, with determination of kinetic curve. After the X-ray diffraction analysis, results show that the sample consists mainly of palygorskite and dolomite. Illite, chlorite and quartz are also determined. It was also possible to see that the different types of disaggregation used show no significant differences in the diffraction patterns of the samples. The sand-silt-clay separation, although it is only based on the size of the material, showed a reasonable efficiency for material separation, as the sedimentation tests, where it was noticed that after $24 \mathrm{~h}$, dolomite had disappeared from the supernatant. Determination of the kinetic curve revealed that the adsorption period of $2 \mathrm{~h}$ is not sufficient for phosphorus adsorption, requiring $24 \mathrm{~h}$ to reach the reaction equilibrium. Sorption tests showed efficiency higher than $91 \%$ of the initial phosphorus in solution, and the maximum quantity adsorbed per gram of sample was 0.607 mg. The correlation with the adsorption isotherm models studied, showed better results for Langmuir-Freundlich isotherm, with correlation coefficient of 0.9993, which can be attributed to the fact that adsorption occurs in more than one layer.

Keywords: palygorskite, dolomite, adsorption, phosphorus, agriculture.

\section{INTRODUÇÃO}

Segundo estimativas do Instituto Geológico y Minero de España a participação dos minerais industriais no Valor da Produção Mineral Mundial é da ordem de 18\%. No Brasil, incluindo-se a categoria de Agregados Minerais, as estimativas de participação são da ordem de $70 \%$ do Valor de Produção Mineral Nacional [1]. Estes dados mostram 
a importância dos minerais industriais e da descoberta de novas fontes desses minerais para a economia brasileira e mundial. Além disso, entre os cerca de 40 argilominerais existentes, poucos são constituintes dos grupos das argilas industriais e das argilas especiais, uma vez que os mesmos possuem propriedades muito específicas que elevam seu valor tecnológico [2].

Neste trabalho, foi utilizada uma amostra proveniente da bacia de S. Luis-Grajaú, MA, que consiste em uma mistura onde há predominantemente palygorskita e dolomita [3]. A palygorskita, assim como outros argilominerais, possui os requisitos necessários para fazer parte do grupo das argilas especiais, por ser de ocorrência restrita [2].

Pertencente ao grupo das hormitas, a palygorskita é classificada como um argilomineral não planar, do tipo 2:1 e consiste num silicato alumino-magnesiano, onde alumínio e magnésio encontram-se em proporções iguais e sua estrutura pode apresentar substituições isomórficas parciais do magnésio por alumínio e/ou ferro, caracterizando-se como uma superfície ripiforme semelhante aos anfibólios $[3$, 10]. Apresenta estrutura em canal aberto, formando cristais alongados e possuindo aspecto fibroso. A fórmula da cela unitária cristalina é descrita abaixo

$$
\mathrm{Mg}_{5} \mathrm{Si}_{8} \mathrm{O}_{20}(\mathrm{OH})_{2}\left(\mathrm{OH}_{2}\right)_{4} 4 \mathrm{H}_{2} \mathrm{O}
$$

na qual $\mathrm{OH}_{2}$ representa água estrutural e $\mathrm{H}_{2} \mathrm{O}$ representa água preenchendo os microcanais fibrosos do argilomineral.

A dolomita integra o grupo dos carbonatos, consistindo num carbonato de cálcio e magnésio. É composta por 30,4\% de $\mathrm{CaO}$ e $21,95 \%$ de $\mathrm{MgO}$. Na agricultura, a dolomita, é aplicada no solo para corrigir a acidez e promover o crescimento das plantas, uma vez que o cálcio, ao reagir com o hidrogênio em excesso, diminui a concentração dos íons $\mathrm{H}^{+}$, elevando o $\mathrm{pH}$ do solo. $\mathrm{O}$ calcário dolomítico proporciona cálcio e magnésio ao solo, além de neutralizar a acidez gerada por fertilizantes nitrogenados, aumentando o cultivo e o conteúdo orgânico do solo [11]. Por conter uma mistura de dolomita e palygorskita, este material pode ser muito importante para a agricultura, uma vez que, excluindo-se as regiões polares, aproximadamente $30 \%$ dos solos mundiais são ácidos [4, 5]. A acidez é um importante fator de degradação dos solos e representa um dos grandes problemas enfrentados pela agricultura, já que os solos ácidos apresentam várias limitações, o que faz com que a eficiência no uso de nutrientes nestes solos esteja sempre comprometida [6]. Desta forma, para que haja maior eficiência no uso de nutrientes, são necessárias as aplicações de algumas práticas, especialmente as que forneçam: diminuição da acidez do solo; aumento da capacidade de troca catiônica (CTC) e diminuição na capacidade de adsorção de ânions; diminuição da perda de nutrientes; e monitoramento e manejo da fração orgânica e atividade biológica. Para isso, as práticas de calagem, adubação e gessagem são largamente empregadas. A calagem consiste na incorporação de calcário nos solos ácidos. Atualmente, os calcários dolomíticos tem sido preferidos em relação aos calcíticos, uma vez que possuem $\mathrm{MgO}$, mantendo a relação $\mathrm{Ca}: \mathrm{Mg}$ mais próxima ao valor ideal, de 6,5:1. Outro importante fator que deve ser considerado, é que os solos ácidos são pobres em nutrientes, o que na maioria das vezes torna necessária a adição de fertilizantes. Portanto, é de grande importância o uso de um material que adsorva esses nutrientes e que possibilite sua posterior utilização pelas plantas [6-9]. Este trabalho aborda a existência de uma nova ocorrência de palygorskita e dolomita na região de S. Luís-Grajaú, MA, sugerindo um método de beneficiamento e sua aplicação como adsorvente de fósforo.

\section{MATERIAIS E MÉTODOS}

Uma amostra representativa de um nível pelítico inferior da Formação Alcântara foi analisada, com base no trabalho de caracterização mineralógica e química feito previamente [3]. A amostragem realizada foi composta, totalizando 10 kg do mesmo nível, ao longo de vários metros de extensão lateral do afloramento, praia da Baronesa, Alcântara, MA. Esta amostra consiste em uma mistura de predominantemente dolomita e palygorskita [3]. A bacia de S. Luis-Grajaú está localizada, em sua grande parte, no estado do Maranhão, imediatamente ao norte da bacia paleozóica do Parnaíba, com a qual é limitada ao sul pelo Lineamento Estrutural Xambioá. A leste é limitada pelo Lineamento do rio Parnaíba, a noroeste pelo Arco do Capim e a norte pelo Gráben de Ilha Nova [12]. Durante a amostragem do material, foram coletadas oito amostras na falésia da praia da Baronesa, de acordo com perfil confeccionado e conforme detalhado em [3]. Para a realização dos ensaios, toda a amostra in natura foi desagregada com a utilização do britador de mandíbulas e do moinho de rolos, originando a amostra padrão, utilizada nos ensaios seguintes. Com o objetivo de estudar diferentes métodos de beneficiamento, foram separadas cinco alíquotas da amostra padrão, que foram colocadas no shatter box por 1, 2, 3, 4 e 5 segundos, respectivamente. Este procedimento foi realizado para verificar a resistência da estrutura da palygorskita, uma vez que o shatter box proporciona uma desagregação mais intensa. Posteriormente, foi realizada a separação das frações areia, silte e argila. Para isso, foi pesada uma alíquota de $100 \mathrm{~g}$ da amostra padrão, que foi desagregada sob ultrassom e passada na peneira $\# 250$ (abertura $0,062 \mathrm{~mm}$ ), de forma manual e com utilização de água. A quantidade restante na peneira (granulometria acima de $0,062 \mathrm{~mm}$ ) foi considerada como areia. A mistura restante, contendo as frações silte e argila foi colocada na centrífuga a $1.000 \mathrm{rpm}$ durante $2 \mathrm{~min}$, com o intuito de separar essas fases.

Com o objetivo de caracterização mineralógica do material, foram realizados ensaios de difração de raios $\mathrm{X}$ (DRX), fluorescência de raios X (FRX) e microscopia eletrônica de varredura (MEV). Os ensaios de DRX foram realizados em difratômetro X'Pert Pro MPD (PW 3040/60) PANalytical e tubo de raios $\mathrm{X}$ de anodo de $\mathrm{Cu}$, filtro de $\mathrm{Ni}$, detector $\mathrm{X}^{\prime}$ Celerator Real Time Multiple Scanning (RTMS). Os dados foram analisados no software X'Pert HighScore versão $2.1 \mathrm{~b}$ e banco de dados PDF do ICDD. As análises de FRX foram realizadas em espectrômetro WDS 
seqüencial Axios Minerals (PANalytical) e tubo de raios X com anodo de Rh de 2,4 kW e software SuperQ Manager, PANalytical. Foram usados dois métodos de preparação: a) disco fundido, no qual foram usados $1 \mathrm{~g}$ de amostra e $6 \mathrm{~g}$ de fundente (tetraborato de lítio). A mistura foi fundida a 1000 ${ }^{\circ} \mathrm{C}$ por $10 \mathrm{~min}$; b) pastilha prensada, no qual foram usados $3 \mathrm{~g}$ de amostra e 0,9 $\mathrm{g}$ de aglomerante (cera de parafina). Essa mistura foi prensada com 20 ton. Para a realização dos ensaios de MEV foi utilizado o microscópio Zeiss LEO 1430. As imagens foram geradas por detecção de elétrons secundários com $20 \mathrm{kV}$.

Durante o manuseio do material, se verificou que a amostra apresentava fragmentos em três cores: branca, verde e vermelha, o que já era esperado, uma vez que a existência de pelitos presentes neste material com essas tonalidades já havia sido descrita [3]. Desta forma, foram separadas manualmente alíquotas de cada uma das cores, às quais foram submetidas a análises de difração de raios $\mathrm{X}$ e microscopia eletrônica de varredura. Também foi feita análise de microscopia eletrônica de varredura da fração branca do material desagregada em água, uma vez que de acordo com a análise de difração de raios X essa fração apresenta palygorskita.

Com o objetivo de verificar outra forma de beneficiamento, observando-se a possibilidade de separação da dolomita e da palygorskita para usos individuais, foram realizados ensaios de decantação. Nestes ensaios, uma alíquota da amostra padrão foi colocada em um recipiente fechado contendo água e submetido à agitação. Após determinado período, a agitação foi cessada para que fosse promovida a decantação. Foram retiradas alíquotas do sobrenadante imediatamente após a agitação, após $24 \mathrm{~h}$ e após $48 \mathrm{~h}$ para a preparação de lâminas orientadas que posteriormente foram submetidas a análise de difração de raios X.

Para aumentar a área superficial da amostra e obter maior eficiência e homogeneidade nos resultados, foi realizada uma etapa de preparação, antes da sua utilização no ensaio de adsorção. Para isto, foram adicionados $1000 \mathrm{~g}$ da amostra padrão ao moinho de bolas por $1 \mathrm{~h}$ Posteriormente, este material foi passado na peneira de \#250 $(0,062 \mathrm{~mm})$, onde não houve material retido. Este material foi utilizado no ensaio de adsorção de fósforo e recebeu o nome de amostra preparada.

Visando determinar a cinética de adsorção do fósforo, e conseqüentemente o tempo de contato entre a solução e o adsorvente durante os ensaios de adsorção, foram pesados $10 \mathrm{~g}$ da amostra preparada, que foi mantida sob agitação, em agitador magnético, juntamente com $100 \mathrm{~mL}$ de uma solução contendo $50 \mathrm{ppm}$ de fósforo por $24 \mathrm{~h}$. Durante esse tempo foram retiradas alíquotas nos seguintes tempos: $5 \mathrm{~min}, 10$ min, $15 \mathrm{~min}, 30 \mathrm{~min}, 1 \mathrm{~h}, 2 \mathrm{~h}$ e $24 \mathrm{~h}$, que foram filtradas e armazenadas para leitura dos resultados. Na preparação da solução foi utilizado fosfato de potássio monobásico $\left(\mathrm{KH}_{2} \mathrm{PO}_{4}\right)$ diluído em cloreto de cálcio $\left(\mathrm{CaCl}_{2}\right)$ 0,01M. A determinação do fósforo foi feita por colorimetria pelo método do azul de molibdênio [13] e o cálculo da quantidade de fósforo adsorvido por grama de material foi feito por meio da equação $\mathrm{B}$, na qual $q$ representa a quantidade de soluto adsorvida (mg.g $\left.{ }^{-1}\right), C_{i}$ e $C_{f}$ as concentrações inicial e final de fósforo em solução (mg. $\left.\mathrm{L}^{-1}\right)$, respectivamente, $V$ é o volume de solução utilizado (L) e $m$ a massa de adsorvente (g).

$$
q=\frac{\left(C_{i}-C_{f}\right) V}{m}
$$

Para o ensaio de adsorção de fósforo foram pesados $2,5 \mathrm{~g}$ da amostra preparada, que foi mantida sob agitação por $24 \mathrm{~h}$ em $25 \mathrm{~mL}$ de solução de $\mathrm{CaCl}_{2} 0,01 \mathrm{M}$ contendo 20, 40, 50, 80 e $100 \mathrm{ppm}$ de fósforo na forma de $\mathrm{KH}_{2} \mathrm{PO}_{4}$. Após esse período a suspensão foi filtrada e a quantificação do fósforo foi feita por colorimetria, na qual o fósforo adsorvido foi calculado pela diferença entre as quantidades adicionadas e a quantidade restante de fósforo na solução de equilíbrio. Com o objetivo de verificar a correlação dos resultados obtidos experimentalmente nos ensaios de adsorção, foram usados os modelos de isotermas de adsorção de Langmuir, Freundlich, Langmuir-Freundlich, Redlich-Peterson e Tóth [14]. As equações referentes aos modelos são apresentadas na Tabela I [14], na qual $q$ é a quantidade de soluto adsorvido (mg. $\left.\mathrm{g}^{-1}\right), C_{f}$ a concetração de equilíbrio do soluto na solução $\left(\mathrm{mg} \cdot \mathrm{L}^{-1}\right), m$ a capacidade máxima de adsorção $\left(\mathrm{mg}^{-1} \mathrm{~g}^{-1}\right), K$ é um parâmetro de afinidade e $b$ é um parâmetro empírico que varia de acordo com o grau de heterogeneidade da superfície do adsorvente.

Ainda visando verificar a correlação dos resultados obtidos experimentalmente nos ensaios de adsorção, foram calculados os erros de adsorção para cada um dos modelos estudados, usando-se a fórmula [15-17]:

$$
\text { Erro }(\%)=100 \sqrt{\frac{1}{n-p} \sum_{i=1}^{n}\left(\frac{q_{\exp }-q_{\bmod }}{q_{\exp }}\right)^{2}}
$$

na qual $p$ é o número de pontos de adsorção, $q_{\exp }$ é a capacidade de adsorção obtida de forma experimental e $q_{\text {mod }}$ é a capacidade de adsorção calculada a partir do modelo de isoterma.

Tabela I - Equações dos modelos de isotermas de adsorção.

[Table I - Adsorption isotherms equations.]

\begin{tabular}{ccccc}
\hline Langmuir & Freundlich & $\begin{array}{l}\text { Langmuir- } \\
\text { Freundlich }\end{array}$ & $\begin{array}{l}\text { Redlish- } \\
\text { Peterson }\end{array}$ & Tóth \\
\hline $\mathrm{q}=\frac{\mathrm{kC}_{\mathrm{f}}}{\left(1+\mathrm{bC}_{\mathrm{f}}\right)}$ & $\mathrm{q}=\mathrm{kC}_{\mathrm{f}}^{\mathrm{m}}$ & $\mathrm{q}=\frac{\mathrm{kbC}_{\mathrm{f}}^{\mathrm{m}}}{\left(1+\mathrm{kC}_{\mathrm{f}}^{\mathrm{m}}\right)}$ & $\mathrm{q}=\frac{\mathrm{kbC}_{\mathrm{f}}}{\left(1+\mathrm{kC}_{\mathrm{f}}^{\mathrm{m}}\right)}$ & $\mathrm{q}=\frac{\mathrm{kbC}_{\mathrm{f}}^{\mathrm{m}}}{\left(1+\mathrm{kC}_{\mathrm{f}}^{\mathrm{m}}\right)^{1 / \mathrm{m}}}$ \\
\hline
\end{tabular}




\section{RESULTADOS E DISCUSSÃO}

A Fig. 1 mostra o difratograma de raios $\mathrm{X}$ obtido para a amostra estudada. Este resultado se refere à amostra in natura pulverizada manualmente em gral de ágata. Por meio da análise dos picos, o material é composto principalmente por palygorskita devido a existência dos picos em $2 \theta 8,448^{\circ}$, $19,668^{\circ}, 26,774^{\circ}$ e $34,492^{\circ}$ e dolomita de acordo com os picos $30,956^{\circ}, 41,105^{\circ}$ e $44,913^{\circ}$, possuindo também clorita de acordo com os picos $6,238^{\circ}, 12,511^{\circ}$ e $25,023^{\circ} 2 \theta$, ilita evidenciada pelos picos $8,856^{\circ}, 17,560^{\circ}$ e $19,634^{\circ}$ e quartzo, de acordo com os picos $20,858^{\circ}, 26,655^{\circ}, 50,132^{\circ}$ e $59,924^{\circ}$.

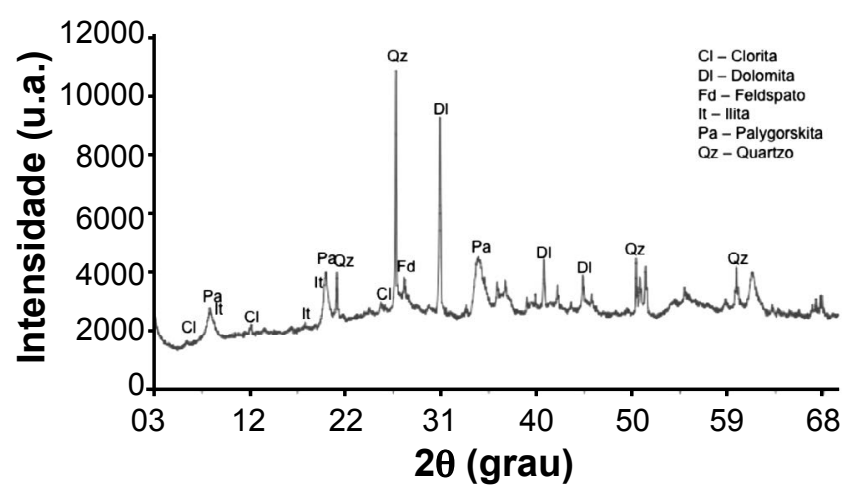

Figura 1: Difratograma de raios $\mathrm{X}$ da amostra in natura.

[Figure 1: XRD pattern for sample in natura.]

$\mathrm{Na}$ Tabela II são apresentados os resultados obtidos pela análise de fluorescência de raios $\mathrm{X}$ da amostra padrão. Os mesmos são comparados a resultados teóricos para a palygorskita e para a dolomita. É importante ressaltar que a amostra estudada se constitui em uma mistura de vários minerais, o que explica algumas divergências de valores. A quantidade de $\mathrm{MgO}$ e $\mathrm{CaO}$ na amostra estudada, que possui resultados inferiores aos da dolomita, pode ser explicada pelo fato da dolomita não ser o único constituinte da amostra. É importante ressaltar que parte do $\mathrm{MgO}$ presente refere-se à palygorskita, já que a mesma consiste em um silicato alumino-magnesiano. Já as concentrações de $\mathrm{Al}_{2} \mathrm{O}_{3}$ e $\mathrm{Fe}_{2} \mathrm{O}_{3}$ podem ser explicadas por substituições isomórficas que provavelmente ocorreram na estrutura da palygorskita. É importante dizer que o valor obtido para a perda ao fogo é aceitável, já que a perda ao fogo da dolomita é referente principalmente à perda de $\mathrm{CO}_{2}$.

Como descrito anteriormente, foram também obtidas imagens de elétrons das alíquotas que foram separadas manualmente, nas cores branco, verde e vermelho; as imagens podem ser visualizadas nas Figs. 2 e 3. Na Fig. 2a tem-se imagens da fração vermelha. Foi admitido que alguns óxidos ou hidróxidos de ferro de baixa cristalinidade possam estar presentes na amostra em quantidades insuficientes para serem detectadas pela análise de difração de raios X, mas suficientes para pigmentar a amostra [3]. Pela análise das imagens pode-se verificar uma heterogeneidade na granulometria do material, que em sua grande maioria apresenta estrutura planar. Na Fig. 2b estão as imagens
Tabela II - Composição química da amostra estudada comparada com resultados publicados.

[Table II - Chemical composition comparative between sample and literature.]

\begin{tabular}{cccc}
\hline & \multicolumn{3}{c}{ Concentração (\%) } \\
\cline { 2 - 4 } Composto & $\begin{array}{c}\text { Amostra } \\
\text { estudada }\end{array}$ & $\begin{array}{c}\text { Palygorskita } \\
{[18]}\end{array}$ & $\begin{array}{c}\text { Dolomita } \\
{[19]}\end{array}$ \\
\hline $\mathrm{SiO}_{2}$ & 48,87 & 58,43 & - \\
$\mathrm{Al}_{2} \mathrm{O}_{3}$ & 14,70 & 6,20 & - \\
$\mathrm{Fe}_{2} \mathrm{O}_{3}$ & 6,53 & - & - \\
$\mathrm{MgO}$ & 5,21 & 14,70 & 21,86 \\
$\mathrm{~K}_{2} \mathrm{O}$ & 3,84 & - & - \\
$\mathrm{CaO}$ & 3,02 & - & 30,41 \\
$\mathrm{TiO}_{2}$ & 0,63 & - & - \\
$\mathrm{SrO}$ & 0,30 & - & - \\
$\mathrm{P}_{2} \mathrm{O}_{5}$ & 0,19 & - & - \\
$\mathrm{Na}_{2} \mathrm{O}$ & 0,18 & - & - \\
$\mathrm{MnO}$ & 0,13 & - & - \\
$\mathrm{SO}_{3}$ & 0,02 & - & - \\
$\mathrm{ZrO}_{2}$ & 0,02 & - & - \\
$\mathrm{Rb}_{2} \mathrm{O}$ & 0,01 & - & - \\
$\mathrm{Perda}$ ao & 16,35 & 19,71 & 47,73 \\
fogo & & & \\
\hline
\end{tabular}

referentes à fração verde do material. Nela também percebemos a presença de um material planar, porém mais homogêneo que o contido na fração vermelha.

Na Fig. 3 estão as imagens obtidas para a fração branca, que foi descrita como sendo a palygorskita [3], informação que se repetiu neste trabalho, sendo confirmada após os resultados de análise de difração de raios $\mathrm{X}$ realizados com essa amostra.

A análise das imagens da Fig. 3 mostra que o mineral presente nesta fração, diferente dos minerais presentes nas demais frações, apresenta uma estrutura tubular e fibrosa, característica pertinente à palygorskita. Também se pode observar um material cimentante unindo as partículas fibrilares de palygorskita ao fundo do feixe principal.

Na Fig. 4 pode-se ver o comparativo dos difratogramas de raios $\mathrm{X}$ das diferentes frações (vermelha, verde $\mathrm{e}$ branca) mostrando a mineralogia de cada uma delas. Após a análise dos difratogramas, é possível verificar que as 3 frações possuem praticamente os mesmos constituintes mineralógicos, já que o processo de separação foi feito de forma manual, o que fez com que pequenas frações de determinada cor continuassem presentes nas outras. Entretanto, pode-se visualizar que a fração branca apresenta os picos característicos da palygorskita $\left(8,295^{\circ}, 19,702^{\circ}\right.$, $26,519^{\circ}$ e $34,560^{\circ}$ ) com intensidade maior que nas outras frações, enquanto na fração vermelha os picos acentuados são os do quartzo $\left(20,875^{\circ}, 26,672^{\circ}, 50,132^{\circ}\right.$ e $\left.59,975^{\circ}\right)$ e na fração verde os da dolomita $\left(30,973^{\circ}, 41,139^{\circ} \mathrm{e} 44,947^{\circ}\right)$. Este 
resultado, somado à análise da Fig. 3, onde se visualiza que a fração branca é a única que apresenta fibras, leva à conclusão que esta fração corresponde ao mineral palygorskita, já que
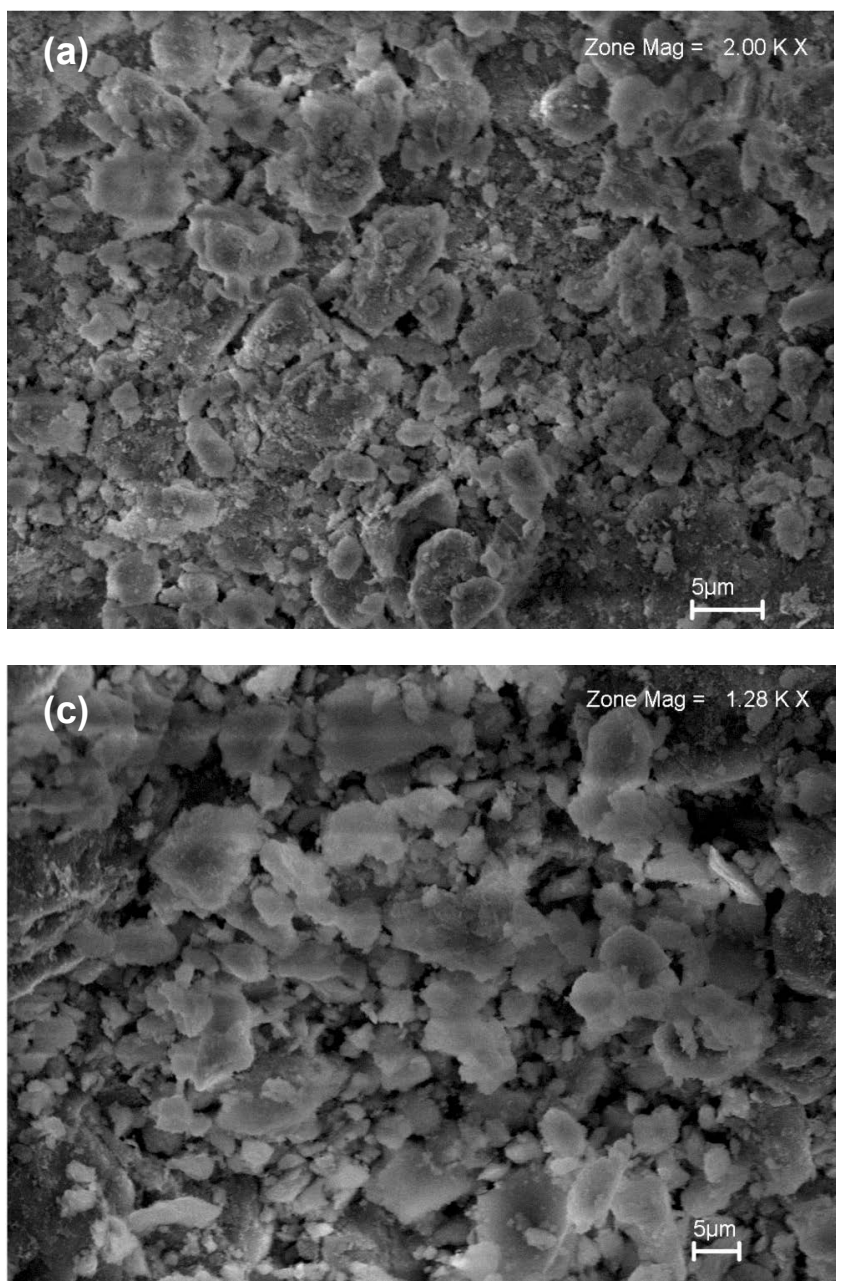

Figura 2: Imagens de elétrons secundários (MEV) obtidas para a fração vermelha (a) e verde (b).

[Figure 2: SEM micrographs of red (a) and green (b) fractions.] o aspecto fibroso é característica pertinente a este material. Desta forma, por ser considerado um material mais nobre e de maior valor agregado, foi realizada ainda a análise de
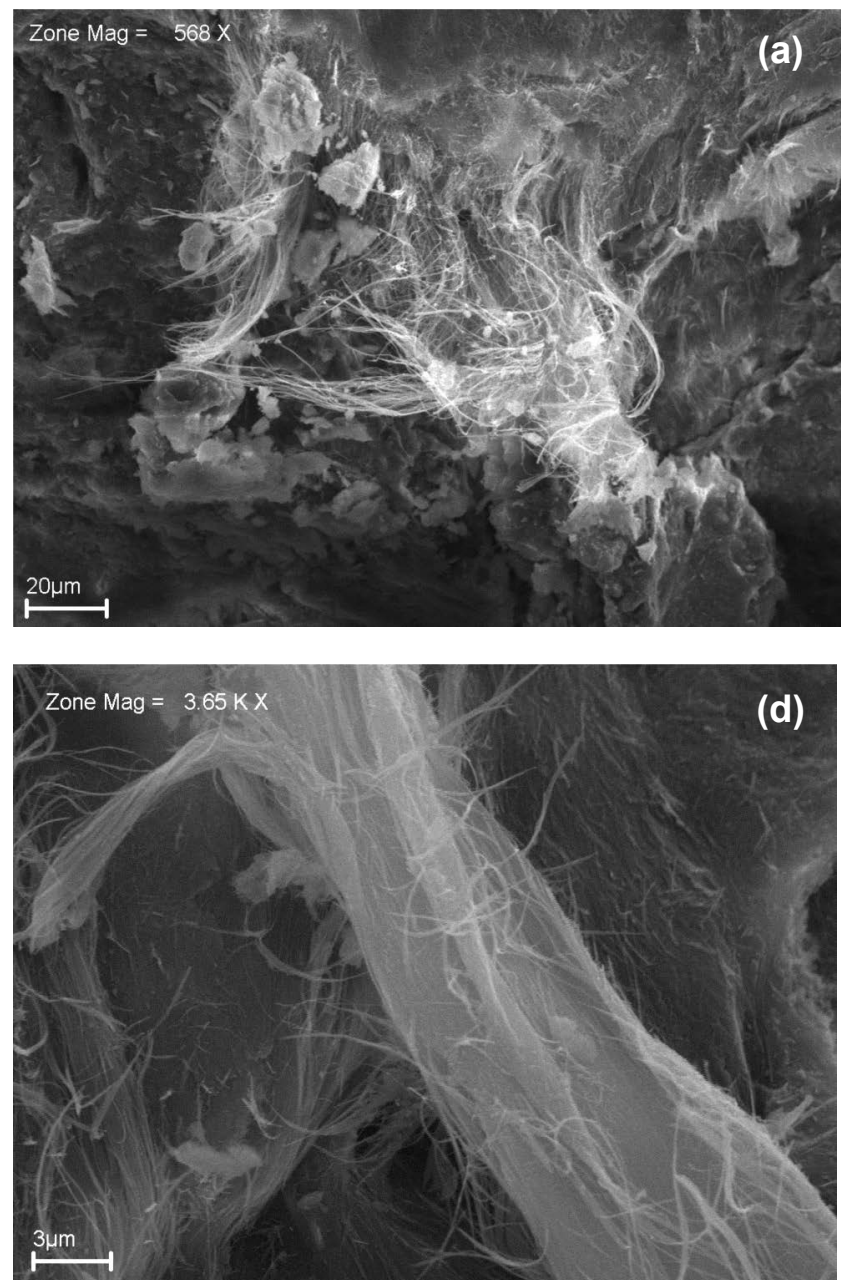

Figura 3: Imagens de elétrons secundários (MEV) obtidas para a fração branca.

[Figure 3: SEM micrographs of white fraction.]

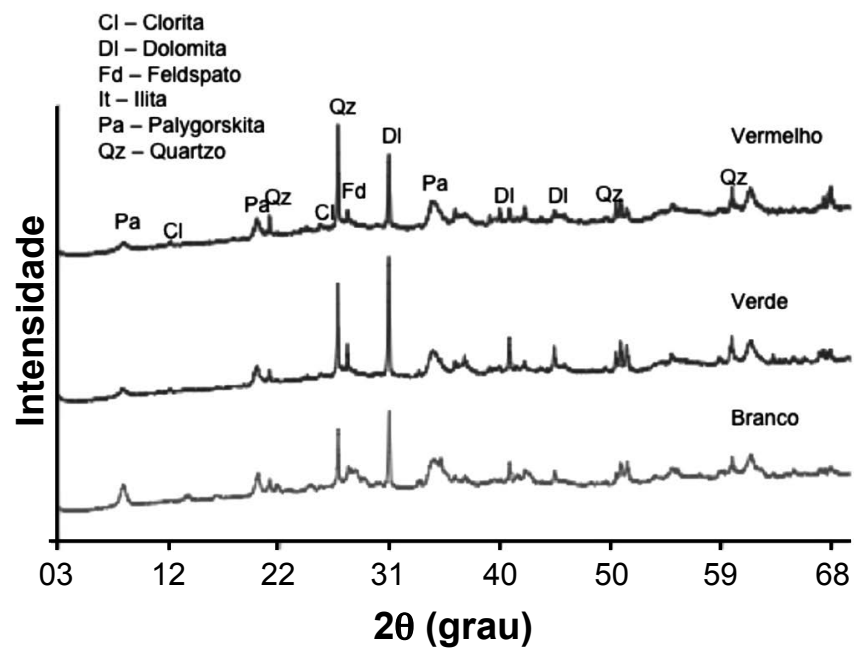

Figura 4: Difratogramas de raios $\mathrm{X}$ das frações vermelha, verde e branca.

[Figure 4: XRD patterns of red, green and white fractions.]

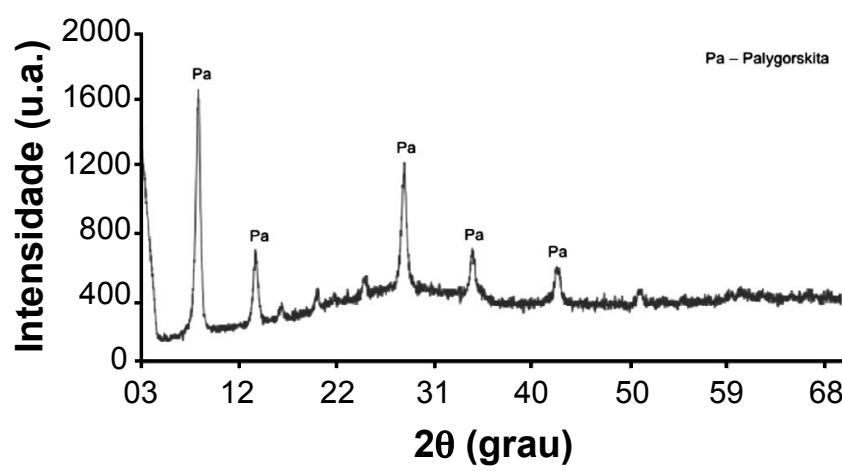

Figura 5: Difratograma de raios $\mathrm{X}$ da fração branca separada manualmente e dispersa em água (lâmina orientada).

[Figure 5: XRD patterns for white fraction manually separated and dispersed in water.] 
difração de raios X somente da palygorskita, usando-se uma alíquota da mesma dispersada em água, da qual foi preparada uma lâmina orientada para análise no difratômetro. O difratograma é apresentado na Fig. 5 e, após a análise dos picos, é possível afirmar que a fração branca corresponde de fato ao mineral palygorskita, de acordo com os picos $8,465^{\circ}$, $13,905^{\circ}, 28,15^{\circ}, 34,628^{\circ}$ e $42,737^{\circ}$.

Os resultados obtidos nas análises de difração de raios $\mathrm{X}$ após os diferentes tipos de desagregação são mostrados na Fig. 6. A análise do difratograma leva à conclusão que o tipo de desagregação, que é bem mais intensa no shatter $b o x$, não exerce influência significativa nas características mineralógicas do material, já que não houve grande variação nas intensidades e nas posições dos picos. Desta forma, dependendo da utilização final deste material, sua desagregação no britador e moinho de rolos já é suficiente, não sendo necessárias outras etapas de desagregação mais vigorosas. Este fato é bem interessante quando se considera a relação custo $\mathrm{x}$ benefício, já que o processamento do material pode ser considerado simples e relativamente barato.

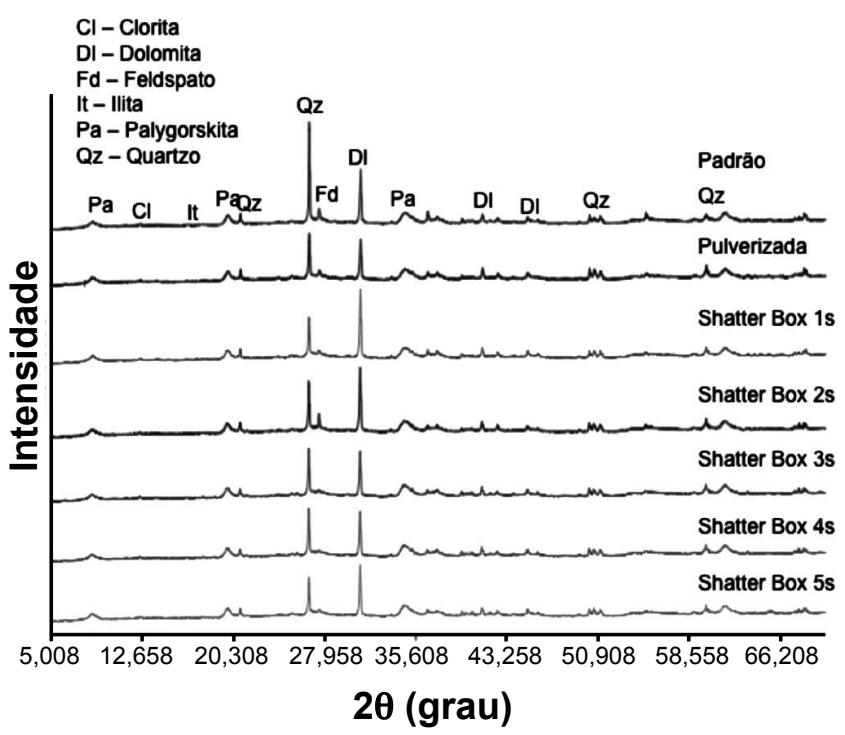

Figura 6: Difratogramas de raios $\mathrm{X}$ das diferentes formas de desagregação da amostra.

[Figure 6: XRD patterns of different disaggregation methods.]

Após a separação das frações areia, silte e argila presentes na amostra, foram obtidos os seguintes resultados: $3,55 \%$ de areia; $58,53 \%$ de silte e $37,92 \%$ de argila. Os difratogramas de raios $\mathrm{X}$ de cada uma das frações podem ser visualizados nas Figs. 7, 8 e 9. A análise do difratograma da fração areia (Fig. 7), que apresenta materiais com granulometria acima de $0,062 \mathrm{~mm}$ (peneira \#250), mostra os picos do quartzo bem intensos $\left(20,875^{\circ}, 26,655^{\circ}, 50,149^{\circ}\right.$ e $\left.59,958^{\circ}\right)$, enquanto os picos da palygorskita $\left(8,567^{\circ}, 20,722^{\circ}\right.$ e $\left.27,471^{\circ}\right)$ são praticamente inexistentes e o da dolomita $\left(30,973^{\circ}\right)$ é de intensidade muito baixa. A análise do difratograma da fração silte (Fig. 8), que contém materiais com granulometria entre $0,062 \mathrm{~mm}$ e $2 \mu \mathrm{m}$, mostra os picos da palygorskita $\left(8,448^{\circ}\right.$, $19,804^{\circ}, 27,488^{\circ}$ e $34,594^{\circ}$ ) com baixa intensidade, além dos picos da clorita $\left(6,221^{\circ}, 12,494^{\circ}\right.$ e $\left.25,142^{\circ}\right)$ e ilita $\left(17,696^{\circ}\right)$ também de baixa intensidade. Por outro lado, observam-se os picos do quartzo $\left(20,858^{\circ}, 26,638^{\circ}, 50,132^{\circ}\right.$ e $\left.59,941^{\circ}\right)$ com intensidade moderada e os da dolomita $\left(30,939^{\circ}\right.$, $41,105^{\circ}$ e $44,930^{\circ}$ ) bem intensos. Por sua vez, a análise do difratograma da fração argila (Fig. 9), contendo materiais com granulometria inferior a $2 \mu \mathrm{m}$, mostra picos da palygorskita $\left(8,499^{\circ}, 19,838^{\circ}, 26,774^{\circ}\right.$ e $\left.34,611^{\circ}\right)$, excluindose os picos do quartzo e da dolomita, que são inexistentes nesta fração.

Os resultados obtidos nesta etapa são de grande importância, uma vez que, embora esse tipo de separação não seja usualmente utilizado para fazer a separação mineralógica

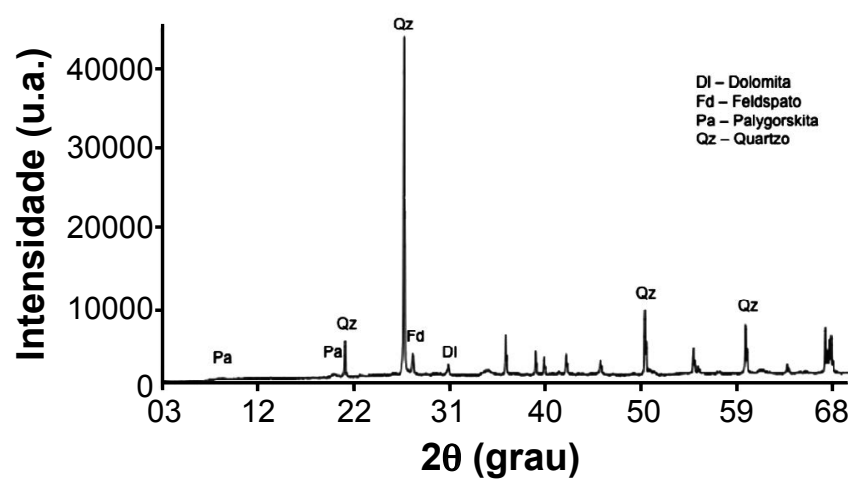

Figura 7: Difratograma de raios $\mathrm{X}$ da fração areia. [Figure 7: XRD pattern of sand fraction.]

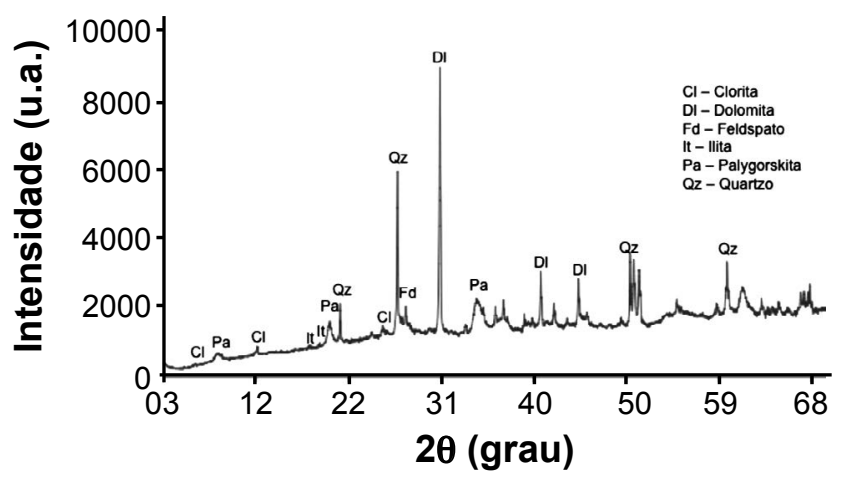

Figura 8: Difratograma de raios X da fração silte. [Figure 8: XRD pattern of the silt fraction.]

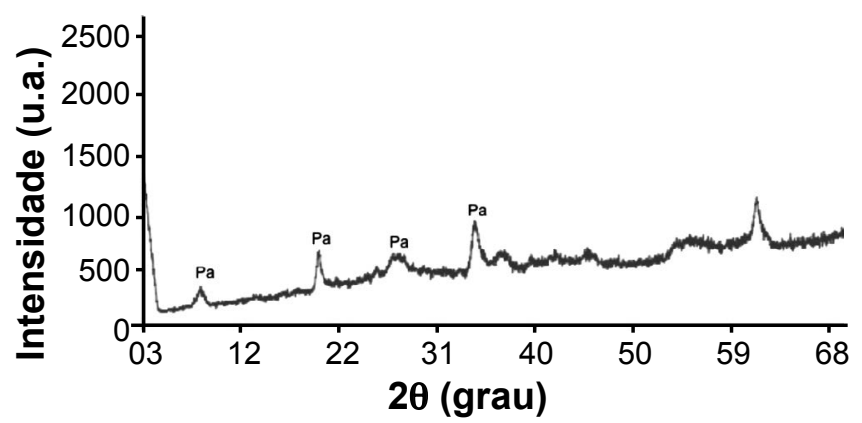

Figura 9: Difratograma de raios $\mathrm{X}$ da fração argila. [Figure 9: XRD pattern of the clay fraction.] 
do material, já que é baseada somente na sua granulometria, independente das fases constituintes da amostra, foi possível verificar que a fração areia é constituída principalmente de quartzo, enquanto a fração silte tem principalmente dolomita e a fração argila contém praticamente só palygorskita. Desta forma, pode-se dizer que o material possui aproximadamente $40 \%$ de palygorskita.

Pela análise do difratograma de raios $\mathrm{X}$ da Fig. 10, referente aos ensaios de decantação, pode-se verificar que imediatamente após o início da decantação, grande parte do quartzo na amostra precipita, de acordo com os picos $\left(20,824^{\circ}, 26,621^{\circ}, 45,440^{\circ}, 50,115^{\circ}\right.$ e $\left.59,499^{\circ}\right)$. Após 24 h os picos referentes à dolomita $\left(30,922^{\circ}\right.$ e $\left.44,709^{\circ}\right)$ são praticamente inexistes. Considerando-se os resultados obtidos após o período de 24 horas, pode-se chegar à conclusão preliminar que a decantação pode ser um método de separação eficiente na separação da dolomita do resto do material. A quantidade de precipitado no fundo do recipiente foi de aproximadamente $60 \%$ do material inicialmente adicionado, o que coincide com os resultados obtidos para a separação das frações de areia, silte e argila.

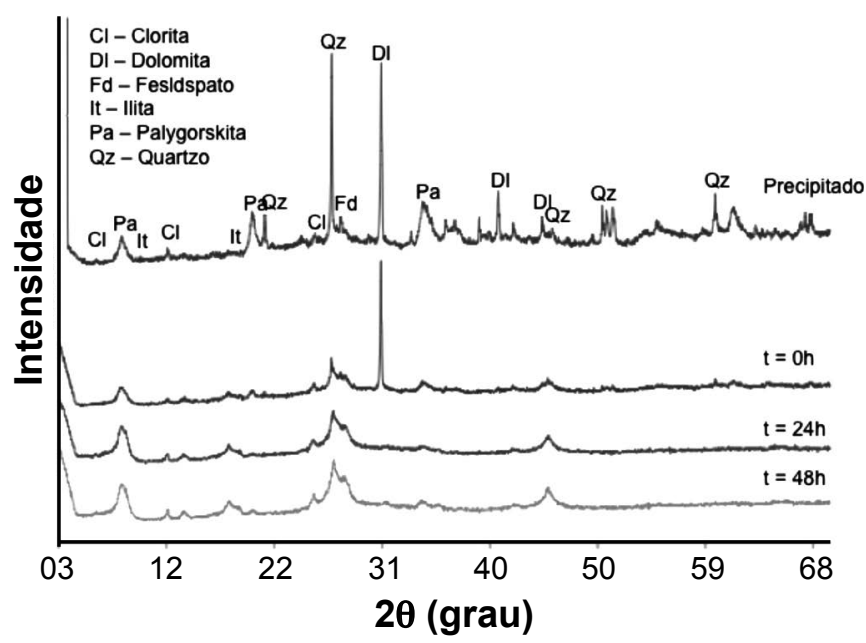

Figura 10: Difratogramas de raios $\mathrm{X}$ do material em suspensão após decantação.

[Figure 10: XRD patterns after precipitation]

Os resultados obtidos para o ensaio de determinação da cinética de adsorção de fósforo são mostrados na Tabela III e nas Figs. 11 e 12. Conforme descrito na literatura, $24 \mathrm{~h}$ é o ideal para que a adsorção seja completa. A análise dos dados da Tabela III mostra que $2 \mathrm{~h}$ não são suficientes para que a reação esteja em equilíbrio. Nesse período a curva cinética havia atingido somente $50 \%$ de sua capacidade total de adsorção. Desta forma, os ensaios de adsorção foram realizados usando $24 \mathrm{~h}$, para garantir que a reação já estivesse em equilíbrio. Foi verificado ainda que a concentração de equilíbrio da solução foi $4,254 \mathrm{ppm}$, ou seja, foram adsorvidos 45,746 ppm dos $50 \mathrm{ppm}$ iniciais. Isto dá 4,57 $\mathrm{mg}$ de fósforo adsorvidas em $1 \mathrm{~g}$ de argila, resultando numa eficiência de 91,49\%.

Os resultados obtidos nos ensaios de adsorção de fósforo são mostrados na Tabela IV, na qual $\mathrm{C}_{\mathrm{i}}$ representa
Tabela III - Resultados obtidos para a cinética de adsorção de fósforo.

[Table III - Phosphorous kinetic adsorption results.]

\begin{tabular}{ccccc}
\hline tempo & $\begin{array}{c}\text { Concentração } \\
\left(\mathrm{mg} . \mathrm{L}^{-1}\right)\end{array}$ & $\begin{array}{c}\text { Quant. } \\
\text { adsorvida } \\
\left(\mathrm{mg} . \mathrm{L}^{-1}\right)\end{array}$ & $\begin{array}{c}\mathrm{q} \\
\left(\mathrm{mg} \cdot \mathrm{g}^{-1}\right)\end{array}$ & $\begin{array}{c}\text { Eficiência } \\
\text { de adsorção } \\
(\%)\end{array}$ \\
\hline 0 & 50,000 & 0,000 & 0,00 & 0,00 \\
$5 \mathrm{~min}$ & 36,368 & 14,632 & 1,46 & 29,26 \\
$10 \mathrm{~min}$ & 34,086 & 15,914 & 1,59 & 31,83 \\
$15 \mathrm{~min}$ & 31,114 & 18,886 & 1,89 & 37,77 \\
$30 \mathrm{~min}$ & 30,896 & 19,104 & 1,91 & 38,21 \\
$1 \mathrm{~h}$ & 30,459 & 19,541 & 1,95 & 39,08 \\
$2 \mathrm{~h}$ & 27,051 & 22,949 & 2,29 & 45,90 \\
$24 \mathrm{~h}$ & 4,254 & 45,746 & 4,57 & 91,49 \\
\hline
\end{tabular}

a concentração de fósforo inicialmente adicionada e $\mathrm{C}_{\mathrm{f}}$ a concentração de fósforo no equilíbrio. A análise dos dados mostra que $1 \mathrm{~g}$ do material tem capacidade de adsorver aproximadamente $0,6 \mathrm{mg}$ de fósforo, em uma concentração inicial de $100 \mathrm{ppm}$ de fósforo. A eficiência obtida durante a adsorção foi bastante promissora, alcançando 91,5\%, em uma concentração inicial de $50 \mathrm{ppm}$ de fósforo.

Os resultados obtidos nos ensaios de adsorção foram correlacionados aos modelos de isotermas de adsorção de Langmuir, Freundlich, Langmuir-Freundlich, RedlichPeterson e Tóth com o programa Statistica 6. Os valores observados para o coeficiente de correlação $\left(\mathrm{R}^{2}\right)$, para os erros de adsorção e para os parâmetros obtidos, podem ser visualizados na Tabela $\mathrm{V}$, enquanto os gráficos das isotermas são mostrados na Fig. 11. A análise dos valores de $\mathrm{R}^{2}$ mostra que o modelo que melhor se correlaciona aos dados de adsorção obtidos é o da isoterma de Langmuir-Freudlich ( $\mathrm{R}$ $=0,9993)$, seguido pelos modelos de Toth $(\mathrm{R}=0,8259) \mathrm{e}$ Langmuir $(\mathrm{R}=0,8244)$.

A análise dos valores de $\mathrm{R}^{2}$ mostra que o modelo que melhor se correlaciona aos dados de adsorção obtidos é o da isoterma de Langmuir-Freudlich $\left(\mathrm{R}^{2}=0,9993\right)$, seguido pelos modelos de Toth $\left(\mathrm{R}^{2}=0,8259\right)$ e Langmuir $\left(\mathrm{R}^{2}=\right.$

Tabela IV - Resultados obtidos nos ensaios de adsorção de fósforo.

[Table IV - Phosphorous adsorption results.]

\begin{tabular}{ccccc}
\hline $\begin{array}{c}\mathrm{C}_{\mathrm{i}} \\
\left(\mathrm{mg} \cdot \mathrm{L}^{-1}\right)\end{array}$ & $\begin{array}{c}\mathrm{C}_{\mathrm{f}} \\
\left(\mathrm{mg} \cdot \mathrm{L}^{-1}\right)\end{array}$ & $\begin{array}{c}\text { Quant. } \\
\text { adsorvida } \\
\left(\mathrm{mg} . \mathrm{L}^{-1}\right)\end{array}$ & $\begin{array}{c}\mathrm{q} \\
\left(\mathrm{mg} \cdot \mathrm{g}^{-1}\right)\end{array}$ & $\begin{array}{c}\text { Eficiência } \\
\text { de } \\
\text { adsorção } \\
(\%)\end{array}$ \\
\hline 20 & 2,68 & 17,32 & 0,173 & 86,6 \\
40 & 3,58 & 36,42 & 0,364 & 91,1 \\
50 & 4,25 & 45,75 & 0,457 & 91,5 \\
80 & 20,45 & 59,55 & 0,595 & 74,4 \\
100 & 39,27 & 60,73 & 0,607 & 60,7 \\
\hline
\end{tabular}


Tabela V - Valores obtidos para o coeficiente de correlação e para os parâmetros nas diferentes isotermas de adsorção testadas utilizando o programa Statistica 6.

[Table V-Obtained values for correlation coefficient and adsorption parameters using the software Statistica 6.]

\begin{tabular}{cccccc}
\hline & Erro (\%) & $\mathrm{R}^{2}$ & $k$ & $b$ & $m$ \\
\hline Langmuir & 35,14006 & 0,8244 & 0,26899 & 0,68976 & - \\
Freundlich & 42,62180 & 0,7284 & 0,23995 & - & 0,27149 \\
Langmuir-Freundlich & 0,94682 & 0,9993 & 0,00485 & 0,60083 & 4,49753 \\
Redlich-Peterson & 42,67795 & 0,7243 & $-17,36648$ & 0,23073 & 0,71806 \\
Toth & 35,36663 & 0,8259 & 0,22952 & 0,81227 & 0,94144 \\
\hline
\end{tabular}
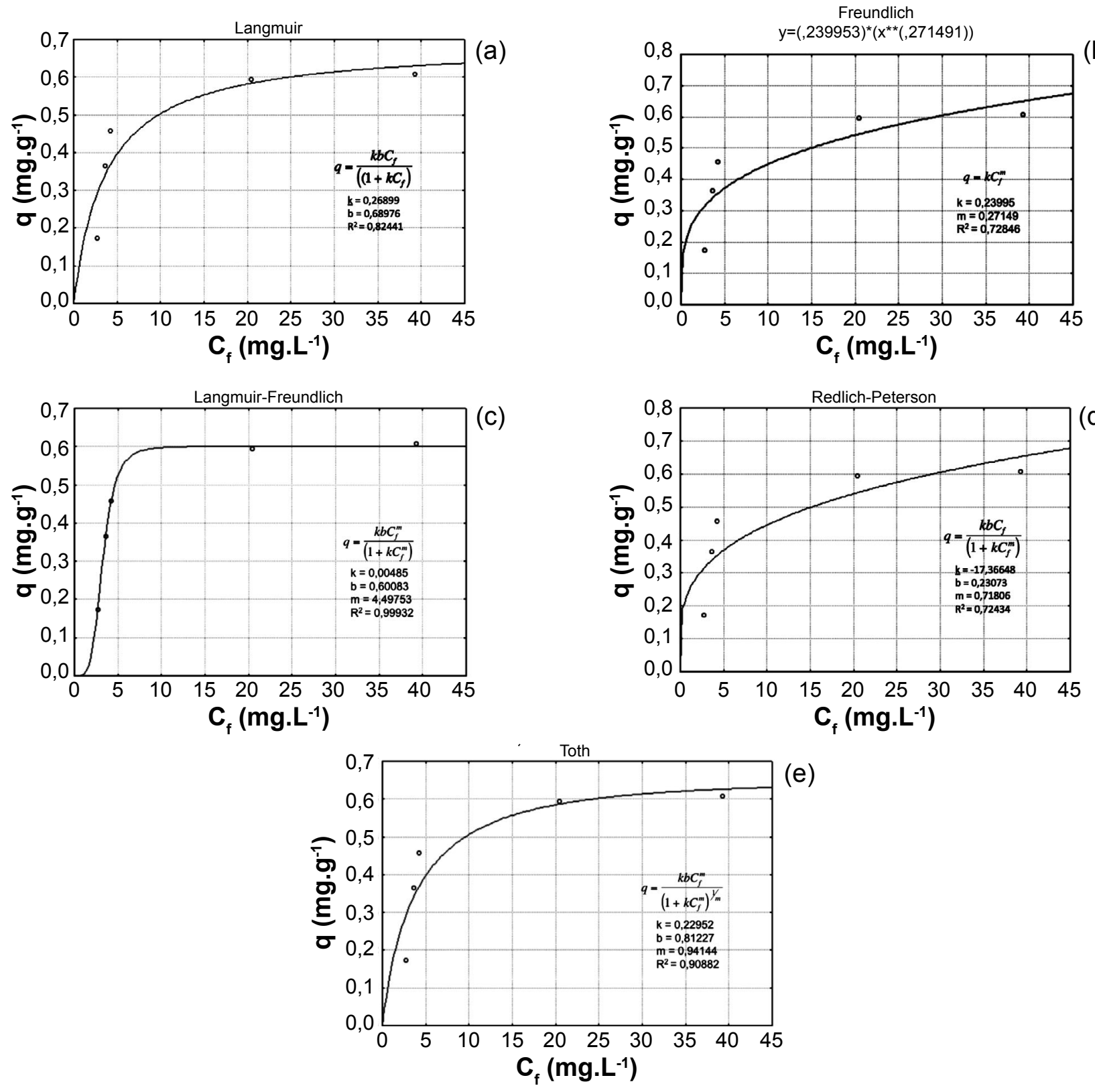

(e)

Figura 11: Correlação entre os dados obtidos e as isotermas de Langmuir (a), Freundlich (b), Langmuir-Freundlich (c), Redlich-Peterson (d) e Tóth (e).

[Figure 11: Correlation between obtained results and Langmuir (a), Freundlich (b), Langmuir-Freundlich (c), Redlich-Peterson (d) and Toth (e) isotherms.] 
0,8244). Este resultado é ratificado pela análise dos valores do erro de adsorção, onde o modelo que possui menor valor é o de Langmuir-Freundlich $(0,94682 \%)$. Já a análise da Fig. 11, comprova aquilo que o coeficiente de correlação havia mostrado: o modelo de isoterma que melhor se correlaciona com os dados obtidos é o de Langmuir-Freundlich. Isto pode ser explicado pelo fato de a adsorção ter ocorrido em multicamadas.

\section{CONCLUSÕES}

Pelos resultados obtidos nos ensaios de caracterização mineral, a amostra estudada é constituída principalmente de palygorskita e dolomita, apresentando também ilita, clorita e quartzo. Como apresenta uma quantidade razoável de palygorskita, de aproximadamente $40 \%$, conforme visto na separação das frações de areia, silte e argila, esta ocorrência pode ser considerada de grande importância, já que a palygorskita é uma argila de ocorrência restrita. Entretanto, embora os resultados sejam promissores, um estudo mais aprofundado da região é necessário para verificar a viabilidade de exploração deste material. A mistura de dolomita e de palygorskita no mesmo minério pode ser de interesse da agricultura, uma vez que a dolomita atua como corretor de solos ácidos e a palygorskita como carreador de nutrientes. Por meio da separação manual do material de acordo com as cores (branco, verde e vermelho) foi possível perceber, após a análise dos materiais, que a fração branca corresponde à palygorskita. Os diferentes tipos de desagregação utilizados não apresentaram interferência significativa nos difratogramas das amostras. Isto significa que, de acordo com o uso pretendido, a amostra está pronta para ser utilizada após desagregação no britador e moinho de rolos, não sendo necessário utilizar outro tipo de desagregação mais intenso. No que se refere à palygorskita, a desagregação mais intensa não provocou modificações significativas na sua estrutura nos tempos utilizados, mostrando que sua estrutura não é tão frágil quanto descrita em algumas literaturas. A separação areiasilte-argila, apesar de se basear somente na granulometria do material, apresenta uma eficiência razoável na separação da palygorskita do restante do material, já que o difratograma da fração argila apresentou praticamente somente os picos referentes à palygorskita. Após um período de decantação de $24 \mathrm{~h}$, a dolomita praticamente desapareceu do sobrenadante, o que leva à conclusão que este método pode ser eficiente na separação da dolomita do restante do material, além de ser viável para a concentração da fase palygorskita do material. De acordo com os resultados dos ensaios de determinação da curva cinética, o tempo de $2 \mathrm{~h}$ não foi suficiente para atingir o equilíbrio na adsorção do fósforo, sendo necessário o tempo de $24 \mathrm{~h}$ para uma adsorção eficiente. Neste intervalo, a argila adsorveu mais de $90 \%$ do fósforo em solução, quando considerada uma concentração inicial de $50 \mathrm{ppm}$ de fósforo. Os ensaios de adsorção mostraram que a amostra é eficiente na adsorção do fósforo, adsorvendo até $91,5 \%$ do fósforo inicialmente presente na solução. $\mathrm{O}$ valor máximo adsorvido por grama da amostra foi de $0,607 \mathrm{mg}$, para uma concentração inicial de 100 ppm de fósforo em solução. A correlação com os modelos de isotermas de adsorção estudados, mostrou melhor resultado para a isoterma de Langmuir-Freundlich, com coeficiente de correlação 0,99931, o que pode ser atribuído ao fato da adsorção ocorrer em mais de uma camada. Este fato foi ratificado pelo valor obtido para o erro de adsorção $(0,95 \%)$ para a isoterma de Langmuir-Freundlich.

\section{AGRADECIMENTOS}

À Universidade Federal do Pará, pelas facilidades no desenvolvimento da pesquisa; à Capes, pelo financiamento do projeto "O Mapa das Argilas do Estado do Maranhão: Cadastramento de Ocorrências e Caracterização Mineralógica e Tecnológica de Matérias Primas Cerâmicas", no qual esta pesquisa está inserida; ao Projeto PROCADAmazônia, da CAPES; e à Kamilla Amorim, por ter cedido as imagens de MEV da Fig.3.

\section{REFERÊNCIAS}

[1] A. F. Da S. Rodrigues (2010). http://www.dnpm.gov.br/ conteudo.asp? IDSecao $=68 \&$ IDPagina $=1461$.

[2] A. C. V. Coelho, P. S. Santos, Química Nova 30 (2007) 146-152.

[3] K. B. Amorim, R. S. Angélica, Cerâmica 57 (2011) 483490.

[4] H. R. Von Uexküll, E. Mutert, Plant Soil 171 (1995) 1-15. [5] V. C. Baligar, N. K. Fageria, "Plant-Soil Interactions at Low pH: Sustainable Agriculture and Forestry Production", A. C. Monitz, A. M. C. Furlani, N. K. Fageria, C. A. Rosolem, H. Cantarella, Brasil (1997) 75-93.

[6] W. J. Goedert, E. Lobato, S. Lourenço, "Plant-Soil Interactions at Low $\mathrm{pH}$ : Sustainable Agriculture and Forestry Production", A. C. Monitz, A.M.C. Furlani, N. K. Fageria, C. A. Rosolem, H. Cantarella, Brasil (1997) 97-104.

[7] A. S. Lopes, L. R. G. Guilherme, Uso eficiente de fertilizantes e corretivos agrícolas: aspectos agronômicos, $2^{\mathrm{a}}$ Ed., ANDA, S. Paulo, SP (1992) 64 p.

[8] C. R. da Silva, Z. M. Souza (1998). http://www.agr.feis. unesp.br/acido.htm.

[9] F. E. Bear, S. J. Toth, Soil Science 65 (1948) 67-74.

[10] L. P. Ribeiro, Geochim. Bras. 10, 2 (1996) 401-415.

[11] J. A. Sampaio, S. L. M. Almeida, Rochas e Minerais Industriais, $2^{\mathrm{a}}$ Ed., CETEM, Brasil (2008) 363-391.

[12] K. B. Amorim, Mineralogia e geoquímica dos pelitos e carbonatos da formação Alcântara, cretáceo superior da Bacia de São Luis-Grajau, Trabalho de Conclusão de Curso, IG-UFPA (2010) 73 p.

[13] N. V. M. Siqueira, "Procedimentos selecionados para análises de elementos principais e traços em materiais geológicos (rochas, solos, sedimentos de correntes, etc) em regime de rotina", Laboratório de Análises Químicas, Departamento de Geoquímica e Petrologia, UFPA(1997) 19 p. [14] M. Klugh, M. N. M. Sanches, M. C. M. Laranjeira, V. T. 
Fávere, C. A. Rodrigues, Química Nova 21 (1998) 410-413. [15] S. J. Allen, G. Mckay, J. F. Porter, J. Colloid Interface Sci. 280 (2004) 322-333.

[16] K. Y. Foo, B. H. Hameed, Chem. Eng. J. 156 (2010) 2-10.

[17] A. Kapoor, R. T. Yang, Gas Separation Purification 3 (1989) $187-192$.
[18] Palygorskite Mineral Data, disponível em http:// webmineral.com/data/Palygorskite.shtml, acessado em 06/2010.

[19] Dolomite Mineral Data, disponível em http:// webmineral.com/data/Dolomite.shtml, acessado em 06/2010.

(Rec. 06/03/13, Ac. 12/10/2013) 